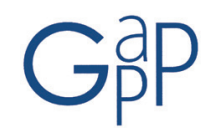

GESTIÓN Y ANÁLISIS DE POLÍTICAS PÚBLICAS, Nueva Época - N.ำ 16, julio-diciembre 2016 - ISSN: $1989-8991$

DOI: http://dx.doi.org/10.24965/gapp.v0i16.10364

Josep Pont Vidal'

Universidade Federal do Pará (UFPA), Brasil

josevidal@ufpa.br

\title{
Modelos innovadores de administración y gestión pública: Hacia la emergencia de nuevos paradigmas ${ }^{2}$
}

\section{Resumen}

La pérdida de legitimidad del sistema político-administrativo, así como las demandas de regeneración política por parte de la ciudadanía y de los movimientos políticos, han obligado a los gobiernos y a la Administración pública, a dar respuestas y a (re)diseñar modelos y lógicas de conducción de lo público. Proponemos una identificación los modelos emergentes y pos-2007 en la Administración y gestión pública en torno a la propuesta de los modelos: continuidad, transición e innovador. Se articula en torno a dos variables explicativas: los conceptos teóricos e ideas subyacentes y las prácticas. Como conclusiones los modelos emergentes propugnan una nueva concepción de Gobierno abierto y los innovadores nuevas formas de gestión (no estratégica).

Palabras clave

Administración pública; gestión pública; modelos emergentes; innovación; Gobierno abierto.

\section{Innovative models of management and public administration: Toward the emergency of new paradigms}

\begin{abstract}
The loss of legitimacy of the administrative-political system, as well as the demands of political regeneration by the citizens and political movements, has forced governments and public administration to give answers and (re) design models and logics of public leading. We have proposed an identification of emerging models and after 2007 in administration and public management around a proposition of the models of: continuity, transition and innovator. It articulates around the explanatory variables: the theoretical concepts and underlying ideas, and the practices. As conclusion, the emerging models aim a new conception of open Government and the innovators in new forms of management (not strategic).
\end{abstract}

Keywords

Public administration, public management, emerging models, innovation, open Government.

1 Profesor Titular de Teoría de las organizaciones, Administración pública y Políticas Publicas, del Núcleo de Altos Estudos Amazônicos (NAEA) Universidade Federal do Pará (UFPA).

2 Agradezco a los evaluadores por sus pertinentes sugerencias y comentarios. Realizado con el apoyo financiero de la Coordenação de Aperfeiçõamento de Pessoal de Ensino Superior (CAPES) Brasil, núm.: 99999.001896/2014-08. 


\section{INTRODUCCIÓN}

La crisis económica y financiera iniciada en el año 2007 ha puesto al descubierto y acentuado unos problemas latentes ya existentes en el último cuarto de siglo en el sistema político-administrativo y en modelos anteriormente hegemónicos de gestión y gobernanza. Diversos factores han conducido al sistema político-administrativo a la actual situación de desconfianza. Por un lado, la extensión de la crisis económica y financiera y sus impactos, con el dramático aumento del desempleo en la mayoría de países europeos y con profundas consecuencias en las personas y en la cohesión social en diversos ámbitos y la exclusión social (Andrews, et al, 2013; Polavieja, 2013). Por otro, para el sistema político-administrativo, una de las consecuencias ha sido la desafección de la política y la pérdida de confianza hacia las instituciones por parte de la ciudadanía3

Las propuestas y los intentos de corregir esta situación mediante el impulso de diversos modelos de participación «top down» no han dado los resultados esperados, puesto que se ha invitado a la ciudadanía a la participación, sin que se recompusieran previamente las relaciones de confianza entre el sistema y la sociedad civil y de la ubicación de los actores emergentes ${ }^{4}$. Las movilizaciones ciudadanas y de jóvenes (Mareas en España durante el año 2011) que han ido acompañadas de la emergencia de movimientos políticos y nuevos actores políticos han tenido impactos para el sistema político-administrativo (Peña-López, et al, 2014). Estos movimientos políticos reivindican una «revolución» democrática de las instituciones y del sistema político, y cuestionan los modelos y las prácticas de las administraciones y de la gestión pública, entre otras exigencias 5 .

Las administraciones y organizaciones públicas se encuentran en este escenario marcado por una crisis económica que sobrepasa estos límites para convertirse en sistémica y con la exigencia de tener que responder a nuevos desafíos y a las demandas. En este contexto, la innovación aparece como la palabra clave y necesaria (Longo, 2012; Kohli y Mulgan, 2010, además de convertirse en un «criterio de competitividad» (Zapico, 2012:8), apareciendo como «fundamental» para lograr «hacer más con menos» (Feinstein, 2012:146).

En este trabajo pretendemos contribuir a la reflexión sobre los diferentes modelos y prácticas de Administración y gestión pública actuales innovadores, intentando dar un especial énfasis a los modelos y propuestas surgidas post-2007. De estos modelos y prácticas surgen interrogantes sobre los que intentaremos responder dos interrogantes: el primero, ¿qué aportan de nuevo o innovador los modelos surgidos después de la crisis?, el segundo ¿qué marco referencial y conceptual subyace en cada uno de estos modelos? Son diversos los marcos conceptuales que en los últimos años han intentado dar respuestas a estos interrogantes (teoría de la elección racional, public choice theory, neo-institucionalismo, teorías de las redes). El proceso de identificación y análisis se inscribe en la lógica observacional sistémica (autorreferencial) y una perspectiva constructivista (interpretativa) ${ }^{6}$. La lógica propuesta se fundamenta en la premisa de que la perspectiva del observador siempre produce un sesgo en su observación de la realidad. En consecuencia de ello, la identificación que proponemos debe ser entendida como una aproximación. Para responder las preguntas formuladas las limitamos a dos variables: primera, los conceptos teóricos subyacentes en estos modelos y propuestas emergentes, la segunda, la tipología estructural de los modelos post-2007.

Las preguntas tienen su origen en la hipótesis central de este escrito: la crisis que irrumpe en el año 2007 ha tenido impactos en las prácticas en la administración y gestión pública. Sin embargo, en la mayoría de los casos los modelos considerados innovadores ya existían, remontándose sus raíces teóricas a conceptos ya aplicados previamente (incluso en la década de los años 1990), por ello, no nos referimos a un cambio de paradigma, sino a la aparición de diferentes modelos y prácticas de gestión. La aparición de un nuevo paradigma es todavía discutible y emerge tan solo en prácticas y experiencias concretas.

El objetivo del escrito es la identificación y análisis de los modelos que pueden ser considerados como innovadores. Poder aproximarnos a identificar estos modelos (o paradigmas) nos ofrece también una serie de pistas para

3 En una perspectiva explicativa de la "desafección política” y de la "desconfianza”, “decepción”, "desconexión” y “desinterés” de los ciudadanos en las democracias occidentales, ver: JAVIER MAROTTE, El campo semántico de la desafección política, 2014; MARIANO TORCAL, Desafección política en España en una perspectiva comparada, 2014. Josep María, Vallés, ¿Regeneración democrática sin contexto? Las condiciones difíciles para un cambio, 2016.

4 La desafección de los ciudadanos con el sistema político-administrativo se remonta en la mayoría de países europeos a mediados de los años 1980, aunque varía en cada país. Los efectos e impactos de la crisis, han puesto de manifiesto y acentuado malas prácticas, corrupción, mal uso y una gestión deficiente e insuficiente.

5 Entre estos, hay que añadir otros retos que sobrepasan las fronteras nacionales como los ambientales, energéticos, sostenibilidad, utilización del agua y migratorios mundiales que han obligado a los gobiernos a (re)diseñar y proponer nuevos modelos y lógicas de conducción de la gobernanza.

6 Sobre la perspectiva que proponemos ver: Josep Pont, “Autopoiesis, autoorganización y cierre operativo en las organizaciones desde la perspectiva postestructuralista” Revista Internacional de Organizaciones, 2015, núm. 14, pp. 31-55. 
permear los caminos y tendencias en que estas prácticas pueden influir en la reconfiguración futura del Estado y el cambio político. Los modelos emergentes se enmarcan en los que podríamos definir como un cambio de modelo en la administración y la gestión, o una «transición entre dos épocas» (Subirats, 2012:71).

En base a la propuesta de identificación de modelos, organizamos el trabajo en dos apartados principales en los que describimos los modelos. El artículo empieza introduciendo al lector con los conceptos de innovación en la Administración pública. Sigue una contextualización de la emergencia de nuevos modelos en la lógica de comprensión sistémica. En los apartados cuarto y quinto se exponen en un plano descriptivo los modelos identificados: continuidad y transición y emergentes. Como epígrafe, ubicamos los modelos en una nueva concepción de la gobernanza.

\section{Estrategia metodológica}

La identificación y clasificación de las tipologías en los modelos que proponemos se articula en torno a tres criterios de selección: 1) la delimitación espacial (geográfica) de las fuentes bibliográficas y conceptuales utilizadas; 2) el método de identificación de las diferentes modelos y prácticas de administración y gestión pública; 3 ) las fuentes y los conceptos teóricos utilizadas en los cuadros.

Las aportaciones proceden del espacio geográfico analizado en concreto, en las publicaciones recientes de autores europeos, en especial procedentes del ámbito anglosajón, germánico y español. Dadas algunas similitudes referentes a los modelos y prácticas emergentes de innovación administrativa y sus respectivos análisis, inferimos el ámbito geográfico a algunos autores de países de América Latina (en especial Brasil) y el Caribe. Es evidente que en un trabajo de estas características las referencias no podrán ser exhaustivas, por lo que las limitaremos a las más recientes y citadas en diversas publicaciones. El método de identificación de las prácticas lo definimos como modelos (o «universos de discurso», como puntualizó Kuhn7 invocando a Wittgenstein). Como resultado, proponemos la idea de dos modelos que ponen de manifiesto las diferentes prácticas: el modelo de continuidad y el modelo innovador.

\section{INNOVACIÓN EN LA ADMINISTRACIÓN PÚBLICA}

Introducimos de forma sucinta la idea de innovación de los procesos gerenciales (gerencia pública) ${ }^{8}$. La mayor parte de la literatura considera la innovación en la Administración y gestión pública como una «necesidad» (Longo, 2012:52) al existir un «innovation deficit in public services» (Potts, 2009:35), por lo que adquiere un interés al tratarse también de un criterio de competitividad (Maddock, 2009; Mulgan, 2009; Kohli y Mulgan, 2010; Moore y Hartley, 2010). El concepto de innovación en el sector público está influenciado por la pluralidad de enfoques existentes «dispersos», y su carácter «polisémico y elusivo» (Ramírez-Alujas, 2012:7) y que vienen a representar diferentes corrientes teóricas e interpretaciones. Esta variedad de puntos de vista contrasta también con una falta de estudios empíricos, cuya debilidad de observaciones es atribuida por algunos autores a la falta de perspectivas de la disciplina académica de las Ciencias de la administración («miopía disciplinaria», Windrum; Koch, 2008). A este hecho, hay que añadir que ha estado influida por la visión de que el concepto de innovación estaba vinculado al aparato productivo, en el cual el sector de servicios considerado como «improductivo» (Ramírez-Alujas, 2012:17) ${ }^{9}$.

En un plano conceptual es posible diferenciar entre la innovación incremental (orientada a la forma de operar) y que implica «mejoras en el rendimiento operativo» de los procesos de producción y de previsión de servicios (Zapico, 2012:8) y la innovación transformacional que supone modificaciones en las estructuras y afecta las responsabilidades y relaciones de poder internas y externas de la administración ${ }^{10}$.

7 A pesar de la similitud semántica entre "modelo" y "paradigma", en este trabajo nos abstenemos de utilizar la denominación de paradigma, dado que este último concepto implica una "cosmovisión" del conjunto de experiencias o Weltanschauung (DILTHEY). En el sentido dado por KUHN, paradigma se refiere a un modelo de problemas para solucionar problemas a una comunidad científica. Pensamos que la definición de "modelo" se ajusta mejor a describir una serie de prácticas, acciones y aplicación de conceptos, mientras que paradigma posee un significado epistemológico de alcance mayor. No obstante, algunos autores del área de la Administración se refieren también a "paradigma" (Villoria, 2012:72).

8 La innovación de los procesos gerenciales y en la administración pública se caracteriza por la publicación de numerosos trabajos en los últimos años (MADDOCK, MULGAN, PotTs, KOHLI Y MULGAN, MOORE Y HARTLEY). Con ello se refleja que el concepto en el sector público también la pluralidad de enfoques existentes "dispersos" y el carácter "polisémico y elusivo" producto de diferentes corrientes teóricas (RAMíREZALUJAS, 2012:7).

9 Referente a las características de la innovación en la administración pública, RAMíREZ-ALUJAS y VILLORIA (2012:22) son incisivos al respeto: "no toda innovación es positiva, al igual que no toda continuidad es negativa".

10 Para FEINSTEIN la naturaleza de la innovación pública puede ser directa o indirecta. Entre la innovación directa menciona: 1. innovaciones directas de proceso, por ejemplo la introducción del presupuesto participativo; 2. innovaciones directas de productos o servicios, como 
Como prácticas administrativas emergentes e innovadoras en la Administración y gestión pública entendemos que estas han de poseer tres características básicas de este tipo de prácticas. Nos referimos a la innovación ${ }^{11}$ de los procesos gerenciales y en la administración pública (....). La innovación en la administración pública se caracteriza por la publicación de numerosos trabajos en los últimos años (Maddock, 2009; Mulgan, 2009; Potts, 2009; Kohli y Mulgan, 2010; Moore y Hartley, 2010). Con ello se refleja en el concepto de innovación en el sector público también la pluralidad de enfoques existentes «dispersos» y el carácter «polisémico y elusivo» (Ramírez-Alujas, 2012:7), aunque también constata una falta de estudios empíricos, como consecuencia de la «miopía disciplinaria» (Windrum, 2008).

Otros autores añaden elementos relacionados con las prácticas realizadas por las organizaciones con el fin de mejorar el producto o servicio que prestan, caracterizado por las ideas de Cambio (cambio radical e impacto), Novedad (es algo nuevo para la organización en cuestión; Acción (supone llevarlas a cabo, no sólo es una «buena idea») (Audit Comission, 2007). También se hace referencia a la introducción de una dimensión social, al añadir que la innovación en el sector público y las nuevas ideas deberían ser capaces de mejorar la operatividad de las instituciones y elevar el nivel de vida de una sociedad.

En este escrito nos referimos a la innovación transformacional y directa, vinculada con modificaciones en las estructuras de la gestión pública y agrega las ideas y prácticas de transparencia, accountability y participación ciudadana. Su observación empírica es una tarea compleja dada la vinculación entremezclada entre los valores y su conexión con las opciones de carácter político (orden externo), así como las relaciones de poder existentes dentro de la administración pública (orden interno). En el orden externo, se manifiesta en su relación con la ciudadanía en del proceso de la co-creación, co-formulación, co-evaluación de las políticas públicas. El elemento central que distingue la innovación del cambio incremental en el impacto del proceso de cambio en la discontinuidad con el paradigma predominante de la organización. Hoy por hoy, gran parte de estas nuevas formas de gestionar lo público se concretizan en torno a la idea de Gobierno abierto (Ramírez-Alujas, 2010, 2011).

La innovación en los procesos administrativos (innovación incremental) habitualmente tiene su origen en las prácticas. La puesta en práctica de las denominadas Best Practices ${ }^{12}$ no es un fenómeno nuevo, sino que tiene su origen en dos supuestos. Por un lado, debido a los procesos innovadores introducidos en la gestión empresarial y en las organizaciones (modelos de motivación, desarrollo personal, logro de objetivos). Por otro, como consecuencia de las reivindicaciones ciudadanas y la consiguiente crisis de legitimidad de la Administración pública que se manifiesta ya partir de la década de los años 1990. La administración pública sufrió un constante deterioro en la que la necesidad de introducir buenas prácticas se volvió una tarea urgente. Las propuestas derivadas de las buenas prácticas, han servido para que se aplicaran propuestas de gestión de forma experimental como ha sucedido en diversos municipios e instituciones de enseñanza superior de América Latina.

\section{CONTEXTUALIZANDO EL ENTORNO: CRISIS ECONÓMICA Y ADMINISTRACIÓN Y GESTIÓN PÚBLICA}

En la óptica de pensamiento de sistemas autorreferenciales, la Administración pública (como parte del sistema político-administrativo, Luhmann, 1991, 1988) constituye uno de los tipos «básicos» de sistemas. El entorno incluye un número infinito de situaciones posibles («entramado desconcertante», Luhmann, 1998:41) al existir unas relaciones de dependencia con el sistema. En esta lógica de pensamiento el entorno de este sistema, que delimitamos y definimos como Administración pública, constituye una estrategia del sistema para su gestión de la complejidad. El entorno esta definido por el constante aumento de la complejidad e influye de forma selectiva en los elementos del sistema Administración pública, con lo cual la complejidad del entorno significa que existen más posibilidades de las que el sistema pueda actualizar y operar. La posibilidad de observar la complejidad de un sistema y de su entorno es mediante una racionalidad selectiva de los elementos del sistema, o sea, a partir de la organización selectiva de la creación de estructuras del sistema (operaciones autorreferenciales). La crisis económica y las demandas de los nuevos actores políticos han impactado directamente en las estructuras propias (autorreferenciales) del sistema Administración pública.

Previa definición del entorno, definiremos lo que denominamos sistema administración pública. En este trabajo lo delimitamos como formado por una serie de operaciones internas (conjunto de estructuras, disposiciones, normas, concursos, burocracia) y diferenciado del sistema político (como el conjunto de toma

un servicio de formación profesional en nuevas tecnologías (FEINSTEIN, 2012:146).

11 En el sector técnico y privado la innovación es entendida como: "la aplicación de una nueva o significativa mejora en un producto (bien y/o servicio) o proceso, un nuevo método de comercialización, o un nuevo método de organización en las prácticas de negocio, lugar de trabajo o en las relaciones externas", Oslo Manual, OECD, 2009.

12 Para catalogar y difundir Best Practices se han creado centros de seguimiento, análisis de estas prácticas (institutos y "bancos", como es el caso del Banco de Buenas Prácticas en Cataluña). 
de decisiones ideológicamente vinculantes, establecimiento de prioridades y límites a la administración) (Luhmann, 1971:64)

Transcurrido más de un cuarto de siglo de la aplicación de la Nueva Gestión Pública, el actual escenario se caracteriza por la complejidad. La crisis financiera global que se inició en el año 2007, ha tenido un fuerte impacto negativo en la Administración pública en los ámbitos estatal, local y municipal en la mayoría de países. Los recursos anteriormente incrementalistas de los estados, se han tenido que reorientar drásticamente para una reducción de costos y asumir de nuevos, para dar atención al enorme desempleo, a las políticas para el desempleo juvenil o el pago la deuda externa, entre otros factores.

En el ámbito municipal se ha producido un cambio de rumbo de prioridades de la administración pública con un aumento de demandas básicas de servicios sociales, asistencia a niños, adolescentes y familias, pago de alquiler de familias necesitadas, programas de pobreza energética, familias en situación de desahucio. Estas necesidades se han vuelto más evidentes a partir del año 2009, cuando los efectos de la crisis económica ya se manifestaban en todos los municipios europeos. Como consecuencia, se propusieron e introdujeron programas de consolidación presupuestaria.

Las administraciones municipales pensadas y acostumbradas anteriormente a una aprobación de presupuestos incrementalista, cuyos ingresos provenían en parte por la especulación inmobiliaria y la construcción (en los municipios españoles representaba una media del 30 por ciento de los ingresos directos) se vieron fuertemente mermadas. Estas administraciones se vieron de repente obligadas a dar respuestas a esta situación y a la necesidad de redirigir la estrategia interna de contención y reducción de gastos, teniendo como consecuencia traumáticas reducciones de funcionarios y servidores públicos como consecuencia de la reordenación y supresión de servicios y áreas. Estas administraciones han tenido que introducir una nueva cultura orientada a objetivos y resultados, así como una financiación sostenible gracias a la introducción de la gestión financiera y los presupuestos estratégicos.

En otro ámbito los desafíos sobrepasan los límites tradicionales de municipio y de nación cuyas cuestiones clave giran en torno a problemas supranacionales como son el cambio climático, la acogida de refugiados, la superación de los efectos económicos y sociales de la crisis, la seguridad y el terrorismo, nuevas formas de producción y consumo, la ciudad sostenible, o el desarrollo humano sostenible. El ciudadano ha pasado de ser entendido como un «cliente» pasivo que consumía servicios públicos para nuevas configuraciones y situarse como «ciudadano activo» que co-participa en la co-confección y co-gestión de las políticas y de los servicios públicos, según las propuestas del Gobierno Abierto y la Nueva Gobernanza.

Se trata de recuperar y revitalizar perspectivas que parten de la autoorganización de la sociedad, cuyas raíces conceptuales provienen de trabajos sobre la autoorganización y el management (Klimecki, 1995) la gobernanza descentralizada (Glagow; Willke, 1987; Willke, 2001), la reformulación de la lógica de la burocracia (Crozier, 1992; Crozier, Friedberg, 1993).

\section{MODELOS EN LA ADMINISTRACIÓN PÚBLICA}

La identificación en modelos que proponemos nos permite una aproximación a la comprensión de la lógica de las reformas. En estas no se trata de un proceso lineal de reformas constantes, sino que aparecen algunas discontinuidades en las que, en especial a partir de la irrupción de la crisis del año 2008, es posible verificar un nuevo periodo o «universo de discurso». Siendo así, nos encontramos hoy por hoy en un espacio temporal de transición y de substitución entre diferentes modelos en la gestión y administración pública. Identificamos entre el modelo de continuidad y el innovador.

El modelo de continuidad, comprende tiene sus inicios en la década de 1990. La relación Estado/mercado se manifiesta por prácticas de externalización de los servicios, mientras que la relación Estado/ciudadano se inspira en las prácticas de gestión empresarial que definen a los destinatarios como «clientes». Bajo la denominación de modelo innovador debe contemplar como mínimo las tres siguientes características: 1) que se fundamenten o impulsen un nuevo tipo de gobernanza (gobernanza en red); 2) que contemplen la rendición de cuentas (accountability) (horizontal y vertical); 3) que incluyan medidas de transparencia como práctica emergente y estratégica.

Es evidente que como sucede en estos casos, no existe una línea clara delimitadora entre los diferentes modelos, como tampoco es posible establecer si los modelos emergentes pos-2008 vienen a ser realmente innovadores en sus prácticas. Tampoco es posible establecer unas líneas claras diferenciadoras entre el Post New Public Management y el Whole-of-goverment approach, al poseer ambos modelos poseen conceptos similares. 
No todos los considerados «nuevos» enfoques y corrientes son realmente nuevos o innovadores. Algunos son meramente prácticas aplicadas para resolver problemas muy concretos a corto plazo, derivadas de marcos más amplios de reformulación de la gestión pública como son adaptaciones del New Public Management. Se trata de acciones concretas adaptadas a las Tecnologías de la Información y la Comunicación (TIC's) y que pueden subsidiar el inicio de nuevos modelos y formas de gestión pública y social, cuyas posibilidades e dudas ya han sido expuestas (Subirats, 2012). Hay que hacer mención a las acciones y estrategias de planificación y de gestión direccionadas para el ámbito económico, que si bien no se trata de nuevos modelos de reformulación de la Administración pública en su totalidad en un sentido amplio, se trata de prácticas más o menos exitosas e innovadoras y que se han aplicado durante algún tiempo con éxito y que se limitan a diferentes niveles o campos específicos de la administración pública general y local como el caso del Common Assestment Framework (CAF).

La perspectiva sistémica que utilizamos se reproduce en la configuración en que se señalan las contingencias a la que está sometido el entorno definido como: estable (con pocos cambios sustanciales), inseguro (expectativas diferentes a las esperadas) y de riesgo (entorno contingente) (Cuadro 1).

CUADRO 1. IDENTIFICACIÓN DE LOS MODELOS EN LA ADMINISTRACIÓN Y GESTIÓN PÚBLICA

\begin{tabular}{|c|c|c|}
\hline Entorno & Modelo & Prácticas \\
\hline Estable & Continuidad & $\begin{array}{l}\text { New Public Management } \\
\text { Procesos financieros: «modernización de la administración» } \\
\text { («Gobernanza estratégica») } \\
\text { Politics and Management Deal (PMD) Common Assestment } \\
\text { Management (CAF) } \\
\text { Best Practices } \\
\text { Open Government Partnership }\end{array}$ \\
\hline Inseguro & Transición «crisis» & $\begin{array}{l}\text { Post New Public Management } \\
\text { Whole-of-goverment approach }\end{array}$ \\
\hline $\begin{array}{l}\text { Riesgo } \\
\text { Complejo } \\
\text { Alta incertidumbre }\end{array}$ & Innovador & $\begin{array}{l}\text { Open government } \\
\text { Nueva gobernanza } \\
\text { Holistic Gobernance }\end{array}$ \\
\hline $\begin{array}{l}\text { Complejo } \\
\text { Alta } \\
\text { Incertidumbre }\end{array}$ & $\begin{array}{l}\text { No-institucional } \\
\text { En implementación/ } \\
\text { Experimentación } \\
\text { (Transition Town) }\end{array}$ & $\begin{array}{l}\text { No-institucional } \\
\text { Social Management/ Gerencia social (1) } \\
\text { Prácticas y proyectos «desde abajo» ("bottom-up”) }\end{array}$ \\
\hline
\end{tabular}

Leyenda: (1) aplicado principalmente en países de América Latina.

En nuestro trabajo hemos elaborado unas dimensiones que posibilitan una aproximación a la identificación de los modelos. Las dimensiones son: configuración, concepción del ciudadano, regulación, procesos, estructura, control y evaluación del desempaño y personal.

Configuración. Organización, actuación y función de las estructuras internas en la administración pública. Cambios de configuración debido a impulsos o comunicaciones (leyes, decretos, etc.) procedentes del sistema político-administrativo (Estado) o de otros sistemas.

Concepción del ciudadano. Derechos que permiten su participación y en las decisiones de la administración y gestión pública y en proceso amplio de políticas públicas. En nuestro enfoque, asume el supuesto fenomenológico husserliano que contempla la situación de hallarse en condiciones de conciencia.

Regulación. La retroalimentación de la administración pública. Disposiciones preestablecidas que en este caso son las prácticas de la regulación jurídica de la función pública.

Procesos. Decisiones internas de la administración pública y los flujos de actividades de planificación, organización y ejecución. 
Estructuras. La forma en que se efectúa la transformación entre las demandas procedentes del entorno y las acciones o respuestas (equilibrio) que ofrece la administración. En concreto, las formas organizativas funcionales entre ministerios, unidades administrativas, sectores, organismos autónomos y la colaboración con otros sectores de la sociedad.

Control y Evaluación del desempeño. La selección y evaluación de las comunicaciones emanadas de la administración pública. En este trabajo, las medidas de la administración pública para ordenar y potenciar los procesos de gobierno y las demandas de la ciudadanía.

Personal. Estrategia de la administración en la institucionalización del servidor público (garantías de permanencia, plano de carrera, capacitación, capacidad de toma de decisiones, promociones, reciclaje).

El análisis de estas dimensiones en los diversos modelos nos permitirá extraer unas tendencias aproximadas sobre ellos. Tal es el caso del modelo que denominamos de "transición". Esta identificación no significa cambios sustanciales respecto a los modelos de continuidad, sino tan solo modificaciones o nuevas prácticas at hoc, introducidas durante la última década por gobiernos de diferente orientación política.

\section{MODELOS DE CONTINUIDAD}

\subsection{New Public Management}

Tras casi tres décadas de aplicación y reformas inspiradas o fundamentadas en la Nueva Gestión Pública (NGP), los estudios y publicaciones internacionales valorativas son tan numerosas, que resulta imposible establecer una aproximación en cada país sobre sus variantes, resultados, aportaciones prácticas y modificaciones (Pollitt, 1995; 2009; Diefenbach, 2009; Barzelay; Gallego, 2006; Erik Lane, 2000) ${ }^{13}$. Son diversos los argumentos que constatan que los principios y teorías que en su día sustentaron la NGP habían «muerto», siendo reemplazada por el gobierno digital y con un mayor enfoque en la «reintegración» (de Vries, 2010; Dunleavy et. al., 2006), constatándose sus «limites» con propuestas de modelos emergentes de gobernanza (Prats, 2005:99-206). Hood ya diagnosticó a finales de la década de los años noventa, que la NGP se encontraba «envejecida», dirigiéndose hacia lo que algunos expertos diagnosticaron ya como «the age of Paradox» ${ }^{14}$. En base a los resultados de su aplicación en diversos ámbitos y países y de las numerosas evaluaciones posteriores realizados, nos permiten identificar el New Public Management (NGP) como el paradigma de la continuidad.

\subsection{Post-New Public Management}

Las limitaciones del modelo expuesto han dado pie a la denominada segunda generación de reformas del sector público, que se concretiza con la introducción de correciones propuestas en la post-NGP. Esta ha adquirido diversas formas e intensidad en cada país, como análisis y estudios han demostrado. La aparición del Post-New Public Management o Nuevo Servicio Público (NSP) (Christensen, 2012; Pérez, et al. 2011), es uno de los modelos emergentes de Administración y gestión pública. La pregunta si realmente se trata de un enfoque «nuevo» o de una reelaboración y adaptación de los anteriores modelos, como la NGP está todavía por responder. Debido a su decline, algunos autores se refieren «más allá de la NGP» (Drechsler, 2009; Moynihan, 2008:485).

En estos análisis se plantean interrogantes relacionados con el extenso y difuso proceso de reformas llevado a cabo en diversos países y se estructuran para ofrecer una visión clarificadora del alcance de implementación del post-NGP. Al igual que en la NGP, la aplicación de un enfoque teórico de observación sobre la transformación en diversos países ha focalizado el desing político (Ramió; Salvador, 2005), o sea, las trayectorias culturales e institucionales y la presión externa para comprender los procesos y los efectos de las reformas introducidas principalmente en la década de los años noventa.

Las reformas post-NGP han sido direccionadas en construir un sentido de valores sólido y unificado. Estos surgen de la formación de equipos con el objetivo de mejorar la capacitación y autodesarrollo de los

13 Después de su aplicación con diferente intensidad, éxito y temporalidad han aparecido voces críticas, anunciando incluso su “fin”. Los resultados empíricos realizados en diversos países que adoptaron este modelo, ya se ha constatado la necesidad de seleccionar tan sólo algunos de sus aspectos (ORMOND; LÖFFLER, 1999).

14 En el plano conceptual se partió de un fuerte instrumental económico (Public Choice, elaborada por OSTROM y NISKANEN) basado en la tríade de los conceptos eficiencia-eficacia-productividad, convirtiéndose y siendo reducido este paradigma un "relato técnico" (MoRıcoNı, 2008:73). 
servidores públicos (como por ejemplo en el Gobierno de Nueva Zelanda). Entre los aspectos débiles aparece la posibilidad de aparición de un «rebustecimiento del núcleo central» que puede crear tensiones y conflictos derivados de la centralización del poder, además de provocar tensión el desafío de equilibrar reafirmación y delegación.

La rendición de cuentas es otro factor de constantes tensiones. Mientras que la NGP ya proporcionó un catálogo de instrumentos de rendición de cuentas, con la tendencia a que estos fueran más claros y transparentes, la segunda generación de reformas de la TG ha sofisticado la propuesta inicial otorgando un papel central (accountability) en el sistema.

Denhardt y Denhardt, en el libro New Public Service. Serving, not Steering (2003) discuten nuevas aportaciones para clarificar las diferencias y similitudes entre el NGP y post-NGP. Esta última se vincula en un ámbito propositivo más normativo, al poner énfasis en la reafirmación de los valores democráticos («citizenship») y el servicio al público interés. No en vano una de sus principales tesis se refiere a que "los empleados públicos no prestan servicios a los clientes, prestan democracia" (Denhardt; Denhardt, 2003: xi).

\section{3. "Whole-of-goverment approach" (Whole of Goverment)}

El modelo aparece en la comprensión de un contexto en el que el mundo es percibido como cada vez más inseguro y peligroso, con riesgos en el algunos países como son el terrorismo y la seguridad interna, y sobre cómo se perciben los cambios y reformas en el sector público (países anglo-sajones, principalmente). En este enfoque se limita al liderazgo político y al administrativo a aplicar formas eficientes de control y de capacidad de direccionamiento y de obtención de información. Esta estrategia no ha estado libre de "problemas de rendición de cuentas y de capacidad" (Christensen; Laegreid, 2007: 542).

El concepto de "Whole-of-goverment approach" o "Totalidad de Gobierno" (TG) 15, surge a partir de los déficits y críticas surgidas de la NGP. Es una propuesta diseñada por expertos y por consultorías especializadas (Christensen; Laegreid, 2006; 2007), apareciendo dudas si realmente se trata de anteriores propuestas y modelos re-formulados (Christensen, 2012; Jun, 2009; Christensen, Laegreid, 2006; Per, 2006; Andreescu, 2003). Los inicios se remontan al periodo iniciado por el gobierno socialdemócrata británico (1997-2007). Se trata de una propuesta nueva para solucionar problemáticas anteriores heredadas de gobiernos y derivadas de fallas de coordinación interinstitucional. Se ha aplicado para analizar y delimitar casos en base a una tipología de enfoques más complejos que se vinculan a la introducción de los modelos de la post-NGP. Con la irrupción de la crisis en el año 2007 , se ha introducido también para optimizar propuestas y ofrecer soluciones debido a la profundidad y extensión en que ha incidido la crisis en diversos países, independientemente del tipo de gobierno que estuviera en el poder.

El concepto de TG tiene como significado práctico que el gobierno y las agencias de servicios públicos deben trabajar entre divisiones para lograr metas compartidas y una respuesta de gobierno integrado, con el fin de proporcionar desarrollo de políticas, dirección de programas y prestación de servicios. Se trata de una serie «coherente de ideas y herramientas» para ofrecer respuestas para el problema de la «fragmentación aumentada» del sector público y los servicios públicos con el objetivo de aumentar la coordinación.

EI TG puede ser interpretado en las perspectivas estructural e instrumental. En la perspectiva estructural los efectos de la crisis han llevado a menudo a plantear a la responsabilización a los líderes políticos ejecutivos de los problemas en las administraciones públicas los cuales han intentado evitar y desviar responsabilidades dirigiéndolas a otros ámbitos de la sociedad mediante la «delegación de responsabilidades» (Christensen; Laegreid, 2007:542). El TG aborda el diseño organizacional consciente y se basa en que los líderes políticos y la Administración pública asuman el diseño estructural de las entidades públicas como instrumentos para cumplir metas públicas. Por otro lado, la perspectiva instrumental sugiere que las organizaciones se encuentran en constante evolución y transformación en su diseño, caracterizado por una adaptación mutua a las presiones internas y externas (entorno). En esta perspectiva, cada organización pública desarrolla a largo plazo normas y valores particulares ya sean institucionales o informales. En ambas perspectivas es importante el liderazgo institucional, al adquirir una dimensión fundamental y ser decisivo en la TG.

Se considera que la política y los cambios en las organizaciones del gobierno central no son necesariamente la herramienta más importante de la reforma para promover iniciativas que «engloban la totalidad del gobierno». La TG aborda la acción política desde los niveles más bajos (lógica «botton up») los más próximos al ciudadano

15 De forma similar al Joint United Goverment o incluso la Holistic Governance (LEAT, SETZLER et al. 2002). 
(municipios, regiones y organizaciones gubernamentales locales) lo cual requiere de proyectos cooperativos y formulados desde la sociedad civil y las entidades sociales (Pollitt, 2003).

Los atentados terroristas de los años 2015 y 2016 en países de la Unión Europea han sido el motivo para aumentar gastos en seguridad y reforzar el papel de los gobiernos en esta área, convergiendo llevando a un «endurecimiento del gobierno» ${ }^{16}$.

\subsection{Fundamentos teórico-conceptuales de los modelos de continuidad}

En un plano político-administrativo, la hipótesis transversal que define estos conceptos tiene su fundamento en la idea de que los políticos y los burócratas de comportan de forma similar a los actores económicos, que significa maximalizar el posible capital político en busca de sus propios intereses. Para equilibrar y superar este reduccionismo economicista, el neo-institucionalismo hace hincapié en las ventajas de la cooperación entre actores (Buchaman), y en el proceso de formación y generación de las instituciones, entendidas «como recursos a las restricciones de la acción individual y socialmente construidas» (North).

Presentamos un esquema comparativo de los conceptos teóricos y centrales de los modelos emergentes de Administración y gestión pública, entre el modelo que definimos como modelo de continuidad. Como fundamentos teórico-conceptuales nos referimos a las teorías constitutivas y a los conceptos funcionales (con característica de teoría y paradigma científico) y las estructuras explicativas subyacentes (Cuadro 2).

CUADRO 2. FUNDAMENTOS TEÓRICO CONCEPTUALES DE LOS MODELOS DE CONTINUIDAD

\begin{tabular}{|c|c|c|}
\hline Modelo & Práctica & Fundamento teórico-conceptuales \\
\hline Continuidad & New Public Management (NPM) & $\begin{array}{l}\text { Lógica sistemas abiertos/cerrados y lineal, } \\
\text { desarrollada en entornos simples, predecibles y } \\
\text { baja resistencia al cambio } \\
\text { Teoría de la elección pública } \\
\text { Teoría económica de la burocracia } \\
\text { Nuevo institucionalismo económico y gerencia } \\
\text { profesional } \\
\text { Three Ms: "mercados-gerentes-medición" } \\
\text { Eficiencia-eficacia-productividad }\end{array}$ \\
\hline \multirow[t]{4}{*}{ Transición } & $\begin{array}{l}\text { Pos-New Public Management } \\
\text { New Public Service }\end{array}$ & $\begin{array}{l}\text { Inspirado en los fundamentos de la NGP } \\
\text { Lógica sistemas abiertos } \\
\text { Énfasis Output-control } \\
\text { Gobernanza social } \\
\text { Reafirmación valores democráticos }\end{array}$ \\
\hline & Politics and Management Deal & $\begin{array}{l}\text { Lógica sistémica de sistemas autorreferenciales } \\
\text { Teoría de los juegos } \\
\text { Lógica mercado }\end{array}$ \\
\hline & Whole-of-goverment approach (WOG) & $\begin{array}{l}\text { Inspirado en los fundamentos de la NGP } \\
\text { Complejidad } \\
\text { Redes informales } \\
\text { Personalización servicios }\end{array}$ \\
\hline & Evidence-Based Policy Making & $\begin{array}{l}\text { Planificación estratégica } \\
\text { Orientación al mercado }\end{array}$ \\
\hline
\end{tabular}

Fuente: Oszlak; O’Donnell (1998); Denhardt; Denhardt (2003), Christensen; Laegreid, (2006; 2007), Barzelay; Gallego (2006), autor.

16 Los últimos atentados terroristas en París del 13 de noviembre de 2015 y del año 2016 han puesto de nuevo en la agenda europea el tema de la seguridad contra el terrorismo. 
Los modelos de gestión pública conocidos como Pos-New Public Management y «Whole-of-government approach» poseen ciertas semejanzas, al tener como raíz común el modelo y las propuestas y principios conductores derivados de la NGP. El modelo Politics and Management Deal aplicado en municipios, cuyos postulados económico-políticos provienen del liberalismo económico.

En los respectivos modelos identificados (continuidad y transición) hemos seleccionado las dimensiones principales que los sustentan y las lógicas que los regulan: configuración, concepción del ciudadano, regulación, procesos, estructura, control y evaluación y personal (Cuadro 3).

CUADRO 3. NUEVOS MODELOS DE GESTIÓN PÚBLICA

\begin{tabular}{|c|c|c|c|}
\hline & $\begin{array}{l}\text { Pos-New Public } \\
\text { Management }\end{array}$ & $\begin{array}{c}\text { "Whole-of-government } \\
\text { approach" }\end{array}$ & $\begin{array}{c}\text { Politics and Management } \\
\text { Deal }\end{array}$ \\
\hline Configuración & $\begin{array}{l}\text { Recentralización: } \\
\text { coordinación horizontal y } \\
\text { vertical }\end{array}$ & $\begin{array}{l}\text { Respuesta a los efectos } \\
\text { no esperados del NPM } \\
\text { (debilitamiento control } \\
\text { político, poca coordinación } \\
\text { áreas gobierno, excesiva } \\
\text { especialización) }\end{array}$ & $\begin{array}{l}\text { Control político, } \\
\text { modelo participativo y } \\
\text { descentralizado }\end{array}$ \\
\hline $\begin{array}{l}\text { Concepción } \\
\text { del ciudadano }\end{array}$ & $\begin{array}{l}\text { Orientación al ciudadano: } \\
\text { responsabilidad y } \\
\text { redención de cuentas. } \\
\text { Participación ciudadana } \\
\text { organizada «desde } \\
\text { arriba» }\end{array}$ & $\begin{array}{l}\text { Revalorización idea del } \\
\text { ciudadano } \\
\text { Participación ciudadana } \\
\text { organizada «desde arriba» }\end{array}$ & $\begin{array}{l}\text { Revalorización idea del } \\
\text { ciudadano. Inicio de la } \\
\text { co-participación ciudadana } \\
\text { (co-formulación políticas } \\
\text { públicas }\end{array}$ \\
\hline Regulación & $\begin{array}{l}\text { Ley administrativa: } \\
\text { obertura y transparencia }\end{array}$ & $\begin{array}{l}\text { Ley administrativa: obertura y } \\
\text { transparencia }\end{array}$ & $\begin{array}{l}\text { Ley administrativa: } \\
\text { obertura, transparencia, } \\
\text { participación }\end{array}$ \\
\hline Procesos & $\begin{array}{l}\text { Revisión y actualización } \\
\text { de las prácticas del } \\
\text { Public Management. } \\
\text { Profesionalización de la } \\
\text { gestión }\end{array}$ & $\begin{array}{l}\text { Prestación de servicios } \\
\text { públicos como respuesta a las } \\
\text { limitaciones de la NGP } \\
\text { Integración vertical y horizontal }\end{array}$ & $\begin{array}{l}\text { Profesionalización de la } \\
\text { gestión } \\
\text { Integración vertical y } \\
\text { horizontal }\end{array}$ \\
\hline Estructura & $\begin{array}{l}\text { Redes de trabajo. } \\
\text { Cooperación entre } \\
\text { organizaciones }\end{array}$ & $\begin{array}{l}\text { Coordinación de diferentes } \\
\text { sectores. Mayor cooperación } \\
\text { mediante fortalecimiento de } \\
\text { redes }\end{array}$ & $\begin{array}{l}\text { Coordinación de diferentes } \\
\text { sectores público-privado. } \\
\text { Mayor cooperación } \\
\text { mediante fortalecimiento } \\
\text { de redes verticales y } \\
\text { horizontales }\end{array}$ \\
\hline $\begin{array}{l}\text { Control y } \\
\text { Evaluación }\end{array}$ & $\begin{array}{l}\text { Control y evaluación de la } \\
\text { gestión (outcome) } \\
\text { Evaluación continua }\end{array}$ & $\begin{array}{l}\text { Evaluación como herramienta de } \\
\text { mejora } \\
\text { Introducción de accountability } \\
\text { Evaluación continua }\end{array}$ & $\begin{array}{l}\text { Evaluación como } \\
\text { herramienta de mejora } \\
\text { Instrumento: Balanced } \\
\text { scorecart } \\
\text { Introducción accountability } \\
\text { Evaluación continua }\end{array}$ \\
\hline Personal & $\begin{array}{l}\text { Profesionalización } \\
\text { funcionariado } \\
\text { Prácticas tercerización }\end{array}$ & $\begin{array}{l}\text { Profesionalización funcionariado } \\
\text { Prácticas tercerización }\end{array}$ & $\begin{array}{l}\text { Profesionalización } \\
\text { funcionariado }\end{array}$ \\
\hline
\end{tabular}

Fuente: Oszlak; O’Donnell (1998); Denhardt; Denhardt (2003), Christensen; Laegreid, (2006; 2007), Barzelay; Gallego (2006), autor. 


\section{MODELOS DE TRANSICIÓN EMERGENTES}

\subsection{Open Government (oGov)}

La idea Open Government (oGov) ${ }^{17}$ no es nueva, al situar algunos expertos sus orígenes en la década de los años 1950, y vincularla con disponer información a la ciudadanía (Cobo, 2012:101). Expertos también lo sitúan con la llegada del presidente norteamericano Bill Clinton, o incluso antes. Independientemente del periodo de sus orígenes o proclamación pública, interesa clarificar de qué se trata exactamente.

El oGov equivale a una mejora de procesos e ideas que ya estaban aplicadas en la administración pública (introducción de tecnologías de la información, Gov.2.0), significando para algunos expertos «una de las mayores innovaciones» (Ramírez-Alujas; Villoria, 2012:20) y al aparecer como un subsistema de políticas públicas.

Para sus impulsores aparece como una nueva forma de relacionarse entre la Administración pública y los ciudadanos y se caracteriza por el establecimiento de una serie de canales de comunicación y contacto directo. Básicamente, el surgimiento de la idea oGov se debe al reconocimiento de los cambios y las exigencias procedentes de la ciudadanía como se desprende de la declaración de la Alianza para el Gobierno Abierto: "que los pueblos del mundo entero exigen una mayor apertura en el gobierno. Piden mayor participación ciudadana en los asuntos públicos y buscan la forma de que sus gobiernos sean más transparentes, sensibles, responsables y eficaces” ${ }^{18}$.

El oGov surge como respuesta a las debilidades de las democracias occidentales (caracterizadas en las últimas décadas por la baja participación ciudadana en los comicios) y en la misma calidad de la democracia que apare como «despolitizada», «dual», «elitista» o «de baja intensidad» (Oszlak, 2013) ${ }^{19}$. Viene también a suplantar la falta de articulación entre las políticas públicas (que se manifiesta en los niveles «horizontal» o sectorial y «vertical» 0 jurisdiccional) ${ }^{20}$ cuyas prácticas han tenido implicaciones en la gestión pública habitualmente concebida en términos sectoriales. Las propuestas de participación provenientes de oGov significan incentivar de los ciudadanos para que puedan participar directamente en el debate de las opciones de políticas públicas, además de aportar ideas y propuestas que se traduzcan a políticas, leyes y decisiones que mejor puedan servir a la sociedad y a los intereses democráticos amplios.

La amplia idea de democracia participativa se constituye como uno de los pilares del oGov, cuyos mecanismos deben permitir a los ciudadanos participar en la toma de decisiones para activar los debates políticos sobre asuntos de interés. El objetivo principal del oGov es establecer una constante interconexión y comunicación con los ciudadanos en sus necesidades y preferencias y escuchar sus demandas, sugerencias y opiniones, facilitando la colaboración con los técnicos y funcionarios públicos en el desarrollo de políticas públicas y servicios.

El concepto de oGov tiene la lógica de un modelo de administración basada en las relaciones, abierta a la ciudadanía y a las demás administraciones y a otras organizaciones colaboradoras por lo que se trata a su vez de una administración en red. La propuesta oGov se fundamenta en tres ejes que dirigen la acción del gobierno en su concreción programática: transparencia, participación y colaboración, y que en la práctica viene a significar la co-producción de políticas y servicios públicos, como se indica en la Alianza para el Gobierno Abierto (en inglés OGP) ${ }^{21}$.

La aplicación de un Gobierno Abierto significa que dispone de elevados niveles de transparencia y mecanismos de escrutinio público y con posibilidades de control con un «énfasis en la responsabilidad del gobierno» ${ }^{22}$. La transparencia se considera su distintivo fundamental y en la práctica significa que la ciudadanía debe tener acceso a la información en poder del gobierno y ser informada de los procedimientos y toma de decisiones gubernamentales. En definitiva, abarca todas las actividades democráticas y de gobierno, por lo que precisamente por ello, puede al final no ser nada (comp. Villoria, 2012:70-74).

Al asumir las experiencias del nuevo institucionalismo (North) y los requisitos de las «buenas instituciones», el oGov se «inserta» en la corriente de buena gobernanza y en la promoción de integridad gubernamen-

17 En: http://www.oecd.org/gov/modernisinggovernmentthewayforward.htm.

18 En: http://www.opengovpartnership.org/sites/default/files/OGP_Booklet_Spanish_Digital.pdf.

19 Para los países de América Latina algunos expertos incluyen las limitaciones de la "accountability horizontal” (COLLIER y LEVITSKY, 1996; O’DONNELL, 1998).

20 Habitualmente ha implicado la división de las funciones y acciones entre las agencias estatales y ministerios, estructura que responde más a consideraciones de especialización funcional que a criterios surgidos de la problemática social y las demandas sociales.

21 "Los gobiernos miembros de OGP se asocian con la sociedad civil para promover la transparencia, empoderar a sus ciudadanos, luchar contra la corrupción y aprovechar las nuevas tecnologías para mejorar la gobernanza de su país. OGP es un movimiento global de reformadores que trabajan para hacer que sus gobiernos sean más efectivos y receptivos con sus ciudadanos".

Ver: http://www.opengovpartnership.org/sites/default/files/OGP_Booklet_Spanish_Digital.pdf.

22 En: https://opensource.com/resources/open-government. 
tal (Villoria, 2012:81). Las raíces teórico conceptuales arrancan principalmente de los polítólogos Oscar Oszlak, Guillermo O’Donnell (1998) y en la perspectiva académica procedente de publicaciones de trabajo social (Yves Vaillancourt en Canadá, 2009 y en Brasil). Sus fuentes se inspiran también en referentes provenientes de la gestión del mundo empresarial («economía abierta»), la economía social (cooperativismo) y de consultorías y grupos de investigación.

El término Gov 2.0 es una especificidad del Gobierno Abierto impulsada por agencias federales norteamericanas, consultorías y empresas transnacionales ${ }^{23}$. Se relaciona con la utilización de las TIC's de colaboración abierta y cuyo objetivo es la creación de una plataforma internacional ${ }^{24}$ a través del cual el gobierno y los ciudadanos puedan trabajar juntos para mejorar la transparencia y eficiencia de los servicios públicos. Se parte de la hipótesis de que la disponibilidad y utilización de las tecnologías de la información deberá favorecer la capacidad de participar en sus gobiernos ciudadanos (Subirats, 2012).

Sin embargo, el conjunto de estas ideas, en especial Open Goverment Partnership y el Gov. 2.0, también han levantado diversas críticas y desconfianza entre la comunidad científica. La idea de colaboración (gobierno, sociedad civil, mercado) es la perspectiva que crea mayores suspicacias debido a la ambigüedad del término, habiendo sido objeto de numerosos análisis y estudios críticos en especial en los países de América Latina ${ }^{25}$ (Kaufman, 2013; Vaillancourt, 2009; Pestoff, 2006, entre otros). Para algunos críticos, se trata además de una estrategia procedente de las élites militares de los Estados Unidos, que tiene como finalidad vincular con la ayuda de las nuevas tecnologías a las respectivas sociedades civiles de los países, a través de una Good Governance. De esta forma, regímenes autoritarios a través de formas de cooperación, pueden llegar a ofrecer una imagen de buen oGov. Por otro lado, si lo que realmente se pretende es un verdadero cambio hacia la transparencia, participación y colaboración, que tenga en cuenta las dimensiones expuestas, deberá tener en cuenta una transformación no solo tecnológica o administrativa, sino también cultural (Cobo, 2012:114). Por último, aparece el interrogante sobre las posibilidades que pueda ofrecer el oGov con la reforma del Estado (Ramírez-Alujas, 2012). Una aplicación técnica y práctica del oGov es la extensión de la e-Administración.

\subsection{E-administración}

La E-Administración no es un modelo de gestión, sino que se limita a un instrumento al servicio de los modelos expuestos. Las ideas y prácticas de e-Administración y e-Government se encuentran entrelazadas con el avance las tecnologías de la información, extendiéndose (ya desde el inicio del siglo actual) entre diversos gobiernos que ya han introducido las prácticas del oGov. Para sus portavoces, e-Administración es un aspecto de la aplicación del e-Government y que significa no disponer tan solo de un nuevo portal de consulta informatizado, sino que se extiende a una reconfiguración de las estructuras de la administración y de los servicios públicos, en base de conocimientos técnicos de la información y de las ciencias de la administración ${ }^{26}$.

La propuesta del e-Government y la introducción de las tecnologías de la información en la administración pública, desencadenan procesos de transformación que no se limitan al sector económico, sino que posibilitan también una creciente demanda específica de funcionarios públicos especializados (Lück-Schneider, 2015).

Sin embargo, para sus críticos la implementación de e-Government no ha ido acompañado de las posibilidades inicialmente pensadas de una modernización de la administración. Las expectativas de ganar en eficiencia todavía no se han constatado en su mayoría. Estos procesos innovadores no significan ninguna ventaja o ganancia palpable para los usuarios, al no ofrecer todavía ventajas prácticas, siendo con ello escasas las posibilidades de confianza.

En la perspectiva gubernamental tampoco existe un consenso sobre la aplicación del e-Government y lo que puede significar para una e-gobernabilidad democrática o una Gobernabilidad electrónica. En el debate es posible visualizar dos perspectivas. Por un lado, la que focaliza las posibilidades que ofrece para construir conexiones que puedan establecer relaciones entre las demandas de políticas públicas y servicios en el ámbito local y las demandas en otros niveles, como en el regional. Por otro, la que aboga por reforzar y profundizar la relación que puede esta-

23 Según la definición de la consultoría internacional Gartner, Government 2.0 tiene siete características principales: It is citizen-driven; It is employee-centric; It keeps evolving; It is transformational; It requires a blend of planning and nurturing; It needs Pattern-Based Strategy capabilities; It calls for a new management style. En: http://blogs.gartner.com/andrea_dimaio/2009/11/13/government-2-0-a-gartner-definition/.

24 Según una síntesis de las diversas conferencias y aportaciones que componen el Summit Gov. 2.0, Washington D. C. 7-8, september 2010.

25 Para información sobre su aplicación en estos países: Ester KAUFMAN, (2013) Disponible en: https://www.oas.org/es/sap/dgpe/pub/ coleccion4RG.pdf.

26 Ver: http://www.ifg.cc/_html/ifgccatwork/publikationen/pdf/lkv1.pdf. 
blecerse entre el gobierno y los ciudadanos. Presiones de los ciudadanos sobre los gobiernos en el plano local para producir servicios eficientes, han llevado a los gobiernos a centrarse más en los aspectos administrativos internos para lograr una mayor eficiencia y eficacia de las políticas públicas.

En suma, la introducción de la e-Administración forma parte del e-Goverment y del conjunto de prácticas del oGov. No obstante, su aplicación deberá compaginarse con la disponiblidad de información para conseguir el denominando «círculo virtuoso» descrito por Pippa Norris (Norris, 2010).

\subsection{Fundamentos teórico-conceptuales de los modelos y paradigmas emergentes}

Siguiendo las dimensiones de los cuadros anteriores, sintetizamos las principales propuestas conceptuales de reforma de la Administración pública, que por sus prácticas y asimilación de nuevos conceptos denominaremos en este trabajo como modelos emergentes: Open government, Nueva Gobernanza Pública y Holistic governance (Cuadro 4).

CUADRO 4. MODELOS EMERGENTES Y DE TRANSICIÓN DE GESTIÓN PÚBLICA

\begin{tabular}{|c|c|c|c|c|}
\hline & $\begin{array}{c}\text { Evidence-Based } \\
\text { Policy Making }\end{array}$ & $\begin{array}{l}\text { Nueva } \\
\text { Gobernanza } \\
\text { Pública }\end{array}$ & $\begin{array}{l}\text { Nueva gobernanza } \\
\text { Holistic governance }\end{array}$ & Open government \\
\hline Configuración & $\begin{array}{l}\text { Pensamiento } \\
\text { estratégico } \\
\text { como un } \\
\text { continuo } \\
\text { Diversos tipos } \\
\text { de planificación }\end{array}$ & $\begin{array}{l}\text { Gobernanza } \\
\text { policéntrica }\end{array}$ & $\begin{array}{l}\text { Marco conceptual } \\
\text { para estudiar } \\
\text { la integración } \\
\text { y coordinación } \\
\text { valores post-NPM }\end{array}$ & Gobernanza interna \\
\hline $\begin{array}{l}\text { Concepción } \\
\text { del ciudadano }\end{array}$ & $\begin{array}{l}\text { Participación } \\
\text { ciudadana y } \\
\text { de actores } \\
\text { estratégicos }\end{array}$ & $\begin{array}{l}\text { Independencia del } \\
\text { ciudadano } \\
\text { Deliberación } \\
\text { pública } \\
\text { Participación en la } \\
\text { decisión }\end{array}$ & $\begin{array}{l}\text { Participación } \\
\text { ciudadana } \\
\text { Accountability }\end{array}$ & $\begin{array}{l}\text { Transparencia } \\
\text { Participación del ciudadano } \\
\text { directamente en la } \\
\text { consideración de opciones } \\
\text { de políticas y la toma } \\
\text { de decisiones. Puede } \\
\text { aportar ideas y pruebas } \\
\text { que conducen a la "co-“" } \\
\text { producción: políticas, leyes y } \\
\text { decisiones }\end{array}$ \\
\hline Regulación & $\begin{array}{l}\text { Adaptación a } \\
\text { los mercados } \\
\text { privados } \\
\text { competitivos }\end{array}$ & $\begin{array}{l}\text { Abertura y } \\
\text { transparencia }\end{array}$ & $\begin{array}{l}\text { Ley administrativa: } \\
\text { obertura y } \\
\text { transparencia }\end{array}$ & $\begin{array}{l}\text { Planes de acción } \\
\text { Instituciones formes e } \\
\text { informales }\end{array}$ \\
\hline Procesos & $\begin{array}{l}\text { Coordinación } \\
\text { de diferentes } \\
\text { planes } \\
\text { Mejora en } \\
\text { la toma de } \\
\text { decisiones }\end{array}$ & $\begin{array}{l}\text { Mejora de la } \\
\text { integración entre } \\
\text { gobierno, sector } \\
\text { privado y } \\
\text { organizaciones } \\
\text { sociales. } \\
\text { Participación } \\
\text { conjuntas en } \\
\text { asuntos comunes }\end{array}$ & $\begin{array}{l}\text { Transparencia, la } \\
\text { retroalimentación, } \\
\text { la mejora continua, } \\
\text { e aprendizaje y } \\
\text { la rendición de } \\
\text { cuentas }\end{array}$ & $\begin{array}{l}\text { Modernización de } \\
\text { accountability } \\
\text { Procesos participativos y de } \\
\text { co-producción } \\
\text { Ciclo participativo } \\
\text { Convivencia de sistemas } \\
\text { formas e informales } \\
\text { Empoderamiento ciudadano }\end{array}$ \\
\hline Estructura & $\begin{array}{l}\text { Coordinación } \\
\text { de los grupos } \\
\text { Priorización de } \\
\text { objetivos }\end{array}$ & Asociación en red & $\begin{array}{l}\text { Asociación o red } \\
\text { (formada por } \\
\text { actores públicos y } \\
\text { privados). }\end{array}$ & $\begin{array}{l}\text { Aprendizaje recíproco Estado- } \\
\text { sociedad }\end{array}$ \\
\hline
\end{tabular}




\begin{tabular}{l|l|l|l|l}
\hline Evaluación & $\begin{array}{l}\text { Evaluación de } \\
\text { los planos }\end{array}$ & $\begin{array}{l}\text { Evaluación de las } \\
\text { políticas públicas } \\
\text { como herramienta } \\
\text { de mejora la } \\
\text { transparencia }\end{array}$ & $\begin{array}{l}\text { Evaluación como } \\
\text { herramienta } \\
\text { de mejora la } \\
\text { transparencia }\end{array}$ & $\begin{array}{l}\text { Modernización de } \\
\text { accountability }\end{array}$ \\
\hline Personal & $\begin{array}{l}\text { Profesionaliza- } \\
\text { ción }\end{array}$ & $\begin{array}{l}\text { Motivación del } \\
\text { servidor público } \\
\text { través de la co- } \\
\text { participación }\end{array}$ & $\begin{array}{l}\text { Profesionalización } \\
\text { funcionariado }\end{array}$ & $\begin{array}{l}\text { Modernización empleo } \\
\text { público. } \\
\text { Motivación del servidor } \\
\text { público }\end{array}$ \\
\hline
\end{tabular}

Fuente: Ramírez-Alujas (2011; 2010); Villoria (2012); Criado, Ignacio (2016); Leat, Setzler et al. (2002); Osborne (2006); Rhodes (1996); Skelcher (2005); autor.

\subsection{Paradigmas y prácticas emergentes de gerencia pública}

Como modelos no-institucionales nos referimos a prácticas surgidas de la sociedad civil (grupos y movimientos alternativos) que se han concretizado en proyectos (constituidos jurídicamente bajo diversas denominaciones: (ONGs, cooperativas, fundaciones, centros autogestionados) y que recogen experiencias de gestión y administración no convencional. El movimiento Transition Town (Hopkins, 2008) constituye una de estas experiencias. Los integrantes y grupos que forman este movimiento, proponen a partir de experiencias prácticas, posibilidades de actuación, de co-producción de políticas sostenibles (ecológicas, ambientales y económicas) y de acciones específicas en esta dirección con los actores que forman la sociedad civil. Se trata de un movimiento en proceso de extensión en numerosos municipios europeos, formado a partir de la colaboración de proyectos, formas cooperativas y asociaciones entre el sector del servicio a las personas y las instituciones del Estado.

\subsection{Social management / Gestión social}

La Gestión Social surge como un conjunto de experiencias procedentes de la sociedad civil'27. Los inicios de este modelo datan de la década de los años 1990 en la que diversos profesores y consultores latinoamericanos cuestionaron la gerencia estrictamente funcionalista y técnica (estratégica) de las democracias occidentales, al proponer la idea de la Gerencia Social. Para sus defensores una de las cuestiones centrales de la propuesta gira en torno a la especificidad de la gestión pública, al poner en cuestión la capacidad y sensibilidad del gestor procedente del sector privado para asumir la gestión pública (Losada, et. al, 1999).

Las raíces e ideas provienen de diferentes corrientes teóricas, centros de análisis y campos que convergen desde diversas perspectivas: la ética cristiana (Klikgsberg, 1989; Jaramillo, 1994), el liberalismo económico bajo principios éticos (Cortázar, 2006) y las aportaciones politológicas de la teoría política latinoamericana de modernización del estado (Oszlak), las teorías procedentes del neo-marxismo (Habermas, Marcuse) y del marxismo analítico e individualismo metodológico (O'Donnell) y el comunitarismo (Tarrow). También se incluye la visión liberal y cristiana de diversas aportaciones de Peter Drucker sobre la gestión de las entidades sin ánimo de lucro y ONG's.

La idea de Gerencia Social (GS) se ha desarrollado básicamente en países Latino Americanos, siendo todavía poco numerosos los estudios en otros países (Sulbrandt, 2002; Goetz; Gaventa, 2001; Johansson, 1994). En este continente los primeros textos sistemáticos que abordan la GS y los problemas que suscita este tipo de gerencia se publicaron en la década de los años 1990 (Klikgsberg, 1994; Losada, et. al, 1999). El núcleo inicial de impulso proviene de un grupo de investigadores y consultores del Instituto de desarrollo Social (INDES) en el Banco Interamericano de Desarrollo (BID). La idea de (GS) es muy amplia al abarcar desde una profesión y la relación con el Estado, la forma de dirigir las instituciones públicas, hasta la «negociación constante con actores y grupos internos» ${ }^{28}$. Las premisas centrales se basan en el marco estratégico integral, entre las que destacan: la gestión en los niveles micro, meso macro, la creación de valor público y la interrelación entre individuos y comunidades (Mokate, Saavedra, 2006; Barcelay; Cortázar, 2004), o más recientemente la vinculación de la innovación social con las políticas públicas (De Marulanda; Tancredi, 2010).

En un plano conceptual y metodológico la GS toma como raíces epistemológicas y referencia la teoría crítica de Jürgen Habermas (1981) y aportaciones de pensadores de la Escuela de Frankfurt (Max Horkheimer y Herbert Marcuse). Estas destacan por su crítica al positivismo de comprensión de los fenómenos y de investigación ideo-

27 Como referencia histórica, aparece en diferentes publicaciones, las experiencias de colectivización y gestión de empresas durante la guerra civil española y las primeras experiencias de soviets en 1918.

28 Alvaro Freddy NAVARRo VARGAS. Disponible en: http://www.ts.ucr.ac.cr/binarios/docente/pd-oo0170.pdf. 
gráfica. En esta perspectiva de pensamiento, la realidad social solo «puede y debe» ser (re)construida para el interés de sus miembros y a partir de sus percepciones.

Brasil es uno de los países en donde el termino GS ha tenido más producción conceptual en publicaciones y tesis de doctorado, cuya vitalidad se manifiesta en la profusión de núcleos de estudio e investigación académicos. También se ha consolidado básicamente como una práctica. Entre los estudiosos de la GS es posible distinguir diversas corrientes conceptuales.

En este país, para sus defensores la construcción del concepto GS parte del binomio habermasiano conceptual Estado-sociedad y capital-trabajo, en el que se invertirse su orden por sociedad-Estado y trabajo-capital (Cançado, 2014; Tenório, 2008). Con esta reformulación se resalta la importancia de las relaciones existentes entre la sociedad y el trabajo. La ampliación de este binomio se amplía al otorgar a la sociedad civil organizada más protagonismo con la introducción de los conceptos sociedad-mercado. En las ideas de democracia deliberativa o participativa propuesta por Habermas, la esfera pública adquiere una posición de espacio intermedio entre el Estado, la sociedad y el mercado. El espacio en el que tendría lugar este entendimiento seria la esfera pública, la cual adquiere un papel clave al cuestionar los procesos técnico-burocráticos y centralizadores cuyas decisiones se fundamentan tan solo en argumentos técnicos.

Otros autores enfatizan los componentes conceptuales en base a la diferenciación entre la gestión pública, la gestión privada (o gestión estratégica) y la Gestión Social (França Filho, 2003; 2008). La GS es entendida a partir de dos perspectivas (como proceso y como finalidad). La Gestión Social como fin «se aproximaría» de la gestión pública, ya que ambas tienen como objetivo ofrecer respuestas a las demandas y necesidades de la sociedad. Pero la Gestión Social como proceso debe procurar: "subordinar las lógicas instrumentales (típicas de la gestión privada/ estratégica] a otras lógicas, mas sociales, políticas, culturales o ecológicas” (França Filho, 2008:30).

\subsection{Hacia una recapitulación de los paradigmas emergentes}

La receptividad de los postulados de la Gestión Social en las teorías de la Administración pública ha sido diversa. Expertos han formulado reiteradamente la cuestión: ¿Cuál sería la diferencia entre una buena gestión pública (estratégica) orientada a la transparencia y al empoderamiento de la sociedad y la Gestión Social? Para los impulsores de la denominada "Gestión Pública Responsable" (Trujillo, et. al, 2011:10) defienden que es necesario establecer diferencias: "ni todas las empresas son malas, ni todas las ONG son buenas, ni todas las Administraciones Públicas son inoperantes" ${ }^{29}$. En una argumentación similar se manifiesta el Centro Latinoamericano de Administración para el Desarrollo, en el que se destacan los objetivos de una buena gestión entre los que destaca la definición de los resultados ${ }^{30}$. (Cuadro 5).

CUADRO 5. FUNDAMENTOS TEÓRICO CONCEPTUALES DE LOS PARADIGMAS DE TRANSICIÓN

\begin{tabular}{l|l}
\hline Paradigma, modelo de transición práctica & Fundamentos teórico conceptuales \\
\hline Open goverment & Lógica sistémica \\
& Accountability \\
Postulados de la co-gobernanza \\
Transparencia, Confianza, Colaboración \\
Aumento de la performance del sector público \\
Sueva gobernanza libre a los principios de la democracia \\
\hline
\end{tabular}

29 Esther TruJILLo et. al. (2011), Manual de Gestión Pública Responsable.

En: http://www.conr.es/descargas/FIIAPP_manual_GPR.pdf.

30 "Vale destacar, para no caer en un gerencialismo equivocado, que el desafío de la gestión pública contemporánea no implica orientarse sólo por el desempeño, sino también implica definir claramente los resultados que se persiguen. El objetivo principal de la administración pública iberoamericana debe ser el de alcanzar el desarrollo en sus distintas facetas: económica, social, política y ambiental. (CLAD, 2010:14). Gestión Pública Iberoamericana para el siglo XXI, Documento aprobado por la XL Reunión Ordinaria del Consejo Directivo del CLAD Santo Domingo, República Dominicana, 8-9 de noviembre de 2010. 


\begin{tabular}{l|l}
\hline Paradigma, modelo de transición práctica & Fundamentos teórico conceptuales \\
\hline Evidence-Based Policy Making & $\begin{array}{l}\text { Fin a la decisión ideológica } \\
\text { Base empírica en la toma de decisiones (indicadores). } \\
\text { Sistémica: Inputs/outcomes } \\
\text { Desarrollo de teoría del cambio } \\
\text { Planificación estratégica } \\
\text { Orientada al mercado }\end{array}$ \\
\hline nodelo o paradigma & $\begin{array}{l}\text { Autorrealización } \\
\text { Autoorganización } \\
\text { Holismo } \\
\text { Desarrollo Humano Sostenible } \\
\text { Centro: persona/ciudadano }\end{array}$ \\
\hline Gestión Social & $\begin{array}{l}\text { Teoría crítica: democracia deliberativa y participativa } \\
\text { (Habsrmas, Horkeimer, Marcuse) Kliksberg } \\
\text { Orientada a la transformación social } \\
\text { Autorrealización, Holismo } \\
\text { Desarrollo Humano Sostenible } \\
\text { Centro: persona/ciudadano } \\
\text { Clara diferenciación entre gestión pública y gestión } \\
\text { privada (o estratégica) }\end{array}$ \\
\hline
\end{tabular}

Fuente: Ramírez-Alujas (2011; 2010); Villoria Mendieta (2012); Criado, Ignacio (2016); Leat, Setzler et al. (2002); Osborne (2006); Rhodes (1996); Skelcher (2005); autor.

\subsection{Nueva Gobernanza y modelos}

La Nueva Gobernanza Pública (NGP) también conocida como Holistic Governance (Leat, Setzler et al. 2002; Osborne, 2006), «new governance» (Rhodes, 1996) y «Public Governance» (Skelcher, 2005) es un conjunto de ideas y formas de gestionar la sociedad. Recientes publicaciones se refieren a la «gobernanza inteligente» (Criado, 2016) o a "collaborative governance regimes» (CGRs) (Kirk y Nabatchi, 2015). Esta heterogeneidad de denominaciones pone de manifiesto una tendencia constante de transformación y adaptación del modelo original de gobernanza. No se trata de un modelo, sino más bien de una práctica y una configuración de un proceso de gobierno "en modo post-gubernamental" (Aguilar; Bustelo, 2010) en el que se ubican los modelos emergentes planteados en los apartados anteriores. El marco de referencia lo constituye el modo de administrar y el cambio gubernativo en forma de asociación o red (formada por actores públicos y privados), y que recientes publicaciones destacan los entornos y la complejidad en la que se enfrentan las organizaciones públicas (Klijn y Koppenjan, 2015).

La Nueva Gobernanza tiene como criterios e ideas conductoras la legalidad o institucionalidad, eficacia social, cuyos ejes principales son: evaluación y gobernanza.

La evaluación como pilar es asumida como una forma para aumentar la rendición de cuentas a la ciudadanía. Con ello pretende también aumentar la calidad democrática a través de la transparencia y la participación ${ }^{31}$. La gobernanza, entendida como el proceso de dirección de la sociedad cuya intencionalidad es definida por el gobierno de forma interdependiente con las organizaciones económicas y sociales.

La especificidad se manifiesta en numerosas acciones de los gobiernos para encontrar soluciones a los problemas públicos o «realizar determinados objetivos y futuros de valía social» (Aguilar; Bustelo, 2010:25). Se acepta la relación de causalidad que implican el diseño y la ejecución de las políticas y programas. La evaluación tiende a concentrarse en la medición de los efectos que provocan los comportamientos de las organizaciones o del propio personal de la administración pública, no cuestiona la estructura de la causalidad. El proceso se fundamenta en tres supuestos. Primero, la corrección del diseño de las políticas públicas y programas. Se supone que esta cadena de operaciones de las políticas y programas implica un ordenamiento claro y preciso de los objetivos y metas y

31 Los gobiernos además de la dirección de la acción pública tienen la responsabilidad de la evaluación como elemento clave para asegurar: "la transparencia, la retroalimentación, la mejora continua, el aprendizaje y la rendición de cuentas" (AGUILAR; BUSTELO, 2010:50). 
una selección de las acciones causalmente idóneas para realizarlas. Segundo, concentra su atención al desempeño gubernamental-administrativo (políticas, programas y servicios). La acción gubernamental debe poseer el control sobre el mundo social para poder reaccionar frente al hecho que no sucedan los efectos previstos y esperados. Para ello deberá analizar las interferencias de otros actores (políticos, económicos o civiles) que siguen sus propias lógicas. Tercero, los actores clave son los operadores directos de las políticas y programas. Sus acciones se enmarcan en sistemas de acción puesto que su operación no depende tan solo de su habilidad o motivación, sino que está condicionada por estructuras (organizativas, jerarquías, normas, reglamentos).

En definitiva, en esta descripción operativa la evaluación adquiere la expresión «como instrumento de fomento y profundización de la democracia» (Aguilar; Bustelo, 2010:30) unida a una creciente «institucionalización de la función de evaluación» en los gobiernos y en las administraciones.

\section{UNAS CONCLUSIONES PROVISIONALES}

Con este trabajo hemos pretendido ofrecer una aproximación a los conceptos subyacentes en los modelos de administración y gestión pública vigentes en la actualidad. Los modelos emergentes innovadores los hemos analizado en base a dos variables: 1) los conceptos teóricos subyacentes 2) la tipología de estos modelos pos-2008. La mayoría de modelos emergentes son en realidad modelos y prácticas ya aplicadas anteriormente y reformuladas y enfoques ad hoc. La irrupción de la crisis económico-financiera y las presiones de la ciudadanía y los nuevos actores han acelerado su implementación efectiva.

A pesar de los intentos innovadores para dar respuesta a las exigencias procedentes del entorno, las demandas ciudadanas van más allá de esta consigna operativa y funcional de estos modelos. La innovación y reestructuración está condicionada por la ideología del partido que asuma el poder en cada país, puesto que un mismo modelo administrativo y de gestión puede ser utilizado y aplicado por diversas opciones ideológicas.

En la lógica luhmanniana, la explicación de Habermas se muestra insuficiente para explicar la pérdida de legitimidad del sistema político, del cual forma parte la administración («disminución de las entradas fiscales» y de la «lealtad» de la masa). El sistema político-administrativo ha perdido confianza y efectividad también por otros factores como son las comunicaciones equivocadas o desfiguradas procedentes de otros sistemas. No nos referimos a las exigencias necesarias de accountability y transparencia (por citar tan solo unas), o a la ética (que se sobreentiende) sino a una posible sobrecarga de exigencias directas al sistema Administración pública. Observaciones empíricas futuras podrán confirmar empíricamente esta hipótesis.

Los nuevos paradigmas de Administración y gestión pública se encuentran en un periodo inicial, cuyas primeras manifestaciones prácticas se traducen en una convergencia entre nuevas formas de gobernanza y transparencia y propuestas no-institucionales (alternativas). Las prácticas surgidas del movimiento Transition Town son una excepción. Fundamentadas en conceptos diferentes (sustentabilidad económica, ecológica y humana) y la Gerencial Social, es posible definirlo como la emergencia de un nuevo paradigma.

La lógica sistémica instrumental se está reconfigurando hacia sistemas en torno a unas comunicaciones más transparentes (participativas) como promulga el oGovernment. El e-Gov y las tecnologías de la información podrán favorecer la capacidad de participar de los ciudadanos, aunque aparecen diferencias sustanciales sobre la relación que puede establecerse entre el gobierno y los ciudadanos, puesto que la aplicación de esta práctica está relacionada con las opciones políticas de los diferentes gobiernos (socialdemócratas, socialdemócratas de izquierda, liberales y conservadores).

La identificación de modelos innovadores y emergentes de administración y gestión pública nos ofrece unas pistas sobre la dirección y formas en la que se está reestructurando y orientando el Estado en la actualidad, así como sus estrategias de gobernanza, aunque como advierten Ramírez-Alujas y Villoria (2012:22), "no toda innovación es positiva, al igual que no toda continuidad es negativa".

La heterogeneidad de modelos y los nuevos escenarios políticos que se abren, posibilitan entrever que los cambios futuros serán en una dirección evolutiva más profundos, como apuntan diversos estudios (Andrews, 2013; Curry, 2014). En el contexto de incertidumbre y complejidad, no habría que extrañar que sea posible entrever que los cambios futuros serán en una dirección evolutiva más profundos.

Surge de nuevo el dilema sobre las posibilidades de que las reformas y la innovación en la Administración y gestión pública se produzcan a partir de impulsos internos del propio sistema (endógenos) o provengan del exterior (exógenos). Aunque no se dispone de datos empírico suficientes para validad esta hipótesis, es posible entrever que la emergencia de los recientes movimiento políticos ha incidido en acalerar los procesos de cambios e innovación. 


\section{BIBLIOGRAFÍA}

AGUILAR, Luis (2008), "Gobernanza: normalización conceptual y nuevas cuestiones", Cuadernos de Liderazgo, núm. 17, Barcelona, ESADE.

AgUILAR, Luis y BUSTELO, María (2010), "Gobernanza y evaluación: una relación potencialmente fructífera", Revista Gestión y Análisis de Políticas Públicas. Nueva Época, 4:23-51.

ANDREESCU, Francesca (2003), Post-new public management models? New templates and possible lessons from a commercialising british public sector organisation. Southampton, UK, University of Southampton. Discussion Papers in Management, M03-13.

ANDREWS, Rys (et al.) (2013), "Public Management reforms and emerging trends and effects on social cohesion in Europe", COCOPS Work Package 6. En línea: <http://www.cocops.eu/wp-content/uploads/2013/12/Deliverable6.1.pdf> (consulta: 16 octubre, 2015).

Audit Commission (2007), Improving information to support decision making: standards for better quality data. National Health Service in England, 1st Floor, Millbank Tower, Millbank, London. En línea: <http://www. uquebec.ca/observgo/fichiers/74317_789.pdf> (consulta: 19 mayo 2015).

BANKS, Gary (2009), Evidence-based policy making: What is it? How do we get it? (ANU Public Lecture Series, presented by ANZSOG, 4 February), Productivity Commission, Canberra. En línea: <http://www.pc.gov.au/ news-media/speeches/cs20090204/20090204-evidence-based-policy.pdf> (consulta: 20 diciembre 2015).

BARZELAY, Michael y CORTÁzAR, Juan Carlos (2004), Una guía práctica para la elaboración de estudios de caso sobre buenas prácticas en gerencia social. Instituto Interamericano para el Desarrollo Social (INDES), Washington D. C., Banco Interamericano de Desarrollo.

CANÇADO, Airton Cardoso y PINHEIRO, Lauro Santos (2014), Gestão Social: Uma Análise Comparada da Produção Científica nos ENAPEGS 2007-2013, set./dez. 2014, v. 3, núm. 3, pp. 15-31. En línea: <http://www.rigs.ufba.br/ pdfs/RIGS_V3_n3_art1.pdf> (consulta: 19 julio de 2016).

CLAD (2010), Gestión Pública Iberoamericana para el siglo XXI, Documento aprobado por la XL Reunión Ordinaria del Consejo Directivo del CLAD. Santo Domingo, República Dominicana, 8-9 de noviembre de 2010.

Сово, Cristóbal (2012), "Gobierno abierto: de la transparencia a la inteligencia cívica", Hofmann, Andrés; RamírezAlujas, Álvaro; Bojórquez-Pereznieto, José-Antonio (coords.) La promesa del gobierno abierto. México D. F.: Itaip, InfoDF, pp. 101-118. En línea: <http://www.lapromesadelgobiernoabierto.info/lpga.pdf> (consulta: 6 mayo de 2016).

CRIADO, Ignacio (2016), Nuevas tendencias en la gestión pública. Innovación abierta, gobernanza inteligente y tecnologías sociales en unas administraciones públicas colaborativas. Madrid, Instituto Nacional de Administración Pública.

CROzIER, Michael (1992), “Entsteht eine neue Managementlogik?”, Journal für Sozialforschung, 32(2):131-140.

CROzIER, Michael y FrIEDBERG, Erhard (1993), Die Zwänge kollektiven Handels. Über Macht und Organization. Frankfurt a. M., Beltz Athenäum.

CURRY, Dion (2014), "The crystal ball of public administration reform: what future predictions tell us about the present", COCOPS Working Paper, núm. 15, June 2014. En línea: <http://www.cocops.eu/wp-content/ uploads/2014/06/WP15.pdf> (consulta: 22 julio de 2015).

Christensen, Tom y LAeGreid, Per (2006), "Agencification and Regulatory Reform", Christensen, Tom; Per Lægreid (eds.), Autonomy and Regulation. Coping with Agencies in the Modern State. Cheltenham, Edward Elgar.

- (2006a), The Whole-of-Government Approach - Regulation, Performance, and Public-Sector Reform. En línea: <http://cms.uni.no/media/manual_upload/145_No6-06_Christensen-Laegreid.pdf> (consulta: 6 junio de 2015).

- (2007), Trascending New Public Management. The trasnformation of Public Sectors Reforms. Hampshire, Ashgate.

CHRISTENSEN, Tom (2012), "Post-NPM and changing public governance", en CHRISTENSEN, "Post-NPM and changing public governance", Meiji Journal of Political Science and Economics, vol. 1. En línea: <http://mjpse. meiji.jp/articles/files/01-01/01-01.pdf> (consulta: 24 de octubre de 2015).

De MARULANDA, Nohra y TANCREDI, Francisco (2010), "De la innovación social a la política pública". Documentos Cepal, Santiago de Chile.

DiefenbaCH, Thomas (2009), "New Public Management in Public Sector Organization: The Dark sides of Managerialist “Englischment”, Public Administration, 87(4):892-909. DOI: 10.1111/j.1467-9299.2009.01766.x.

DRECHSLER, Wolfgang (2009), "The Rise and Demise of the New Public Management: Lessons and Opprtunities for South East Europe", Uprava, letnik VII, 3.

ECHEBARRIA, Koldo y MENDOZA Xavier (1999), "La especificidad de la gestión pública: el concepto de management público”, en LOSADA, Carlos (et. al), ¿De burócratas a gerentes? Las ciencias de la gestión aplicadas a la administración del estado. BID, Washington D. C., pp. 15-46. 
EMERSON, Kirk y NABATCHI, Tina (2015), "Evaluating the Productivity of Collaborative Governance Regimes: A Performance Matrix", Public Performance \& Management Review, 38:717-747. En línea: <http://dx.doi.org/10.1 080/15309576.2015.1031016> (consulta: 2 agosto de 2016).

FEINSTEIN, Osvaldo (2012), “Evaluación y gestión pública innovadora”, Ekonomiaz, 80(2):138-156. DOI: http:// EconPapers.repec.org/RePEc:ekz:ekonoz:2012208.

Fox, Charles y MILleR, Hugh (1996), Post-modern Public Administration: Towards Discourse. London, Sage.

França Filho y Genauto Carvalho de (2003), "Gestão Social: um conceito em construção" Colóquio Internacional sobre Poder Local, 9, 2003, Salvador. Anais..., Salvador: CIAGS/UFBA, 2003. 1 CD ROM.

GOETZ, Anne Marie y GAVENTA, John (2001), Bringing Citizen Voice and Client Focus into Service Delivery. Brighton, Institute of Development Studies.

HABERMAS, Jürgen (1981), Theorie des kommunikativen Handelns. Kritik der funktionalistischen Vernunft, Frankfurt a.M: Suhrkamp.

HOPKINS, Rob (2008), The Transition Handbook. Green Books, Totnes.

HooD, Christopher (1995), "The New Public Management in the 1980's: variations on a thema", Accounting Organizations and Society, 20(2):93-109.

— (1995a), “Contemporany public management: a new global paradigm?”, Public Policy Administration, 10:104-117.

JARAMILLO, César (1994), “La gerencia social: una alternativa para el sector social. La gerencia social y el Nuevo Paradigma de Gerencia”, Revista Universidad EAFIT (96):65-77.

JohANSSON, Henry (et. al.) (1994), Reingeniería de procesos de negocios. México, Limusa.

Jun, Jong (2009), “The Limits of Post-New Public Management and Beyond”, Public Administration Review, 69(1):161-165. DOI: 10.1111/j.1540-6210.2008.01960.x.

KAUFMAN, Ester (2013), Hacia procesos participativos y de co-producción en el gobierno abierto. Red de Gobierno Electrónico de América Latina y el Caribe -Red GEALC-. En línea: <https://www.oas.org/es/sap/dgpe/pub/ coleccion4RG.pdf> (consulta: 9 de enero 2016).

KICKERT, Walter (1993), "Autopoiesis and the science of (public) administration: essence, sense and nonsense”, Organization Studies, 14:261-278.

KICKERT, Walter y KLIJN, Erik-Hans; KoPPENJAN, Joop (1999), Managing Complex Networks. Strategies for the Public Sector. London, Sage Publications. DOI: 10.1177/017084069301400205.

KLIJN, Erik y KoPPENJAN, Joop (2015), “Governance Networks in the Public Sector. Routledge”, Public Performance \& Management Review 38(4)717-747. DOI: http://dx.doi.org/10.1080/15309576.2015.1031016.

KLIKSBERG, Bernardo (1994), Pobreza: un tema impostergable. Nuevas respuestas a nivel mundial. México, FCE.

KLIMECKI, Rüdiger (1995), "Self-organization as a New Paradigm in Management Science?", Management Forschung und Praxis; Diskussions Beitrag, núm. 10.

KoHLI, Jitinder y MulgaN, Geoff (2010), Capital Ideas: How to Generate Innovation in the Public Sector. USA, The Young Foundation.

KOOIMAN, Jan (2003), GOVERNING AS GOVERNANCE. Londres, Sage. DOI: 10.4135/9781446215012.

- (2007), "Exploring the concept of governability", Journal of Comparative Policy Analysis, pp. 171-190. DOI: $10.1080 / 13876980802028107$.

LANE, Jan-Erik (2000), New Public Management. London, Roudletge. DOI: 10.1016/s1096-7494(01)0o038-1.

LEAT, Diana y SETZLER, Kimberley (et al.) (2002), Towards holistic governance: the new reform agenda, Basingstoke, Palgrave. DOI: 10.1093/parlij/gsg026.

LONGO, Francisco (2012), “Innovación en gobernanza: entornos colaborativos y liderazgos relacionales”, Ekonomiaz, 8o(2):46-70.

LOSADA, Carlos (et. al.) (1999), ¿De burócratas a gerentes? Las ciencias de la gestión aplicadas a la administración del estado. Washington D. C., BID.

LUHMANN, Niklas (1991), Soziologie des Risikos, Berlin, Walther de Grwyter.

- (1988), Ökologische Kommunikation. Darmstadt, Westdeutscher Verlag.

- (1981), Soziale Systeme. Grundrisse einer Allgemeinen Theorie. Frankfurt a.M., Suhrkamp.

- (1971), "Komplexität und Demokratie", en Politische Plannung, Opladen. Westdeutscher Verlag.

MARICONI, Marcelo (2008), Retórica política y reformas de la administración pública en América Latina. Estudio crítico y comparado del discurso oficial sobre reformas administrativas en Argentina, Chile y Uruguay. Tesis Doctoral, Universidad de Salamanca.

MAROTTE, Javier (2014), “El campo semántico de la desafección política”, Revista de Ciencia Política de la ciudad de Buenos Aires a la Aldea global, núm. 21, Teoría política e historia. En línea <http://www.revcienciapolitica.com. ar/num21art1.php> (consulta: 25 julio 2016).

MARTínEZ, Rafael y Joseph TULCHIN (eds.) (2006), La seguridad desde las dos orillas. Un debate entre Europa y Latinoamérica. Barcelona, Cidob. 
MoYNiHAN, Donald P. (2008), The Dynamics of Performance Management, Washington, DC., Georgetown University Press.

MOKATE, Karen y SAAVEDRA, José Jorge (2006), Gerencia Social: Un Enfoque Integral para la Gestión de Políticas y Programas. Documentos de trabajo del INDES. Banco Interamericano de Desarrollo. Serie de Documentos de Trabajo I-56. Washington, D. C.

MORIN, Edgar (2004), “Podemos reformar la administración pública?”, Revista del CLAD Reforma y Democracia. núm. 30. En línea: <http://siare.clad.org/revistas/0049683.pdf> (consulta: 23 noviembre 2014).

MYKKÄNEN, Markus y TAMPERE, Kaja (2014), “Organizational Decision Making: The Luhmannian Decision Communication Perspective”, Journal oj Business Quartely, 5(4):131-146. DOI: http://urn.fi/ URN:NBN:fi:jyu-201406252143.

MulGAN, Geoff (2009), The Art of Public Strategy. Mobilizing Power and Knowledge for the Common Good. Oxford University Press.

MulGaN, Geoff (2010), "The Art of Public Strategy: Mobilizing Power and Knowledge for the Common Good”, Public administration, 88(2):592-595. DOI: 10.1111/j.1467-9299.2010.01837 3.x.

NorRIS, Pippa (2002), The Worldwide Digital Divide: Information Poverty, the Internet and Development. En línea: http://www.hks.harvard.edu/fs/pnorris/Acrobat/psa200odig.pdf (consulta: 27 noviembre de 2014).

- (2010), Critical Citizens. Global Support for Democratic Governance. Oxford. En línea: <http://m. friendfeed-media.com/403974eb3d145b541154369705e5da7d54d15d50> (consulta: 17 de marzo 2014). DOI:10.1093/0198295685.001. 001.

OCDE (2011), Government at a Glance 2011, OECD Publishing. En línea: <http://dx.doi.org/10.1787/gov_glance-2011> (consulta: 19 noviembre de 2015).

- (2009), The Measurement of Scientific and Technological Activities Proposed Guidelines for Collecting and Interpreting Technological Innovation Data. Oslo Manual. En línea: <https://www.oecd.org/sti/inno/2367580. pdf> (consulta: 4 de marzo 2016).

O’DONNELL, Guillermo (1998), “Accountability Horizontal”, Agora. Cuaderno de Estudios Políticos, 8(4):5-34.

ORMOND, Derry y LÖFFLER, Elke (1999), “Nueva Gerencia Pública: ¿qué tomar y qué dejar?”, Revista del CLAD Reforma y Democracia, Caracas, 13:143-164.

OsZLAK, Oscar (2013), Gobierno abierto: hacia un nuevo paradigma de gestión pública. Red REALC/OEA/BID. En línea: <https://www.oas.org/es/sap/dgpe/pub/coleccion5RG.pdf> (consulta: 10 de junio, 2014).

PEÑA-LÓPEZ, et al. (2014), "Spanish Indignados and the evolution of 15M: toward networked para-institutions", Journal of Spanish Cultural Studies, vol. 15, Issue 1-2, Special Issue: Spain in Crisis: 15-M and the Culture of Indignation. DOI: http://dx.doi.rg/10.1080/4636204.2014.931678.

PINHO, José Antonio GOMES DE y SANTOS, M. ${ }^{a}$ Elisabete PEREIRA DOS (2015), "Gestão social: uma análise crítica de experiências brasileiras”. Revista do Serviço Público, vol. 66, núm. 2, pp. 257-281. En línea: <http://repositorio. enap.gov.br/handle/1/2312> (consulta: 19 julio de 2016).

PONT VIDAL, Josep (2015), “Autopoiesis, autoorganización y cierre operativo en las organizaciones desde la perspectiva postestructuralista”, Revista Internacional de Organizaciones, núm. 14, pp. 31-55. En línea: <http:// www.revista-rio.org/index.php/revista_rio/article/view/178> (consulta: 3 de marzo 2016). DOI: http://dx.doi. org/10.17345/rio14.31-55.

- (2017), Innovación de la Gestión Pública. Madrid, La Catarata (en edición).

- (2011), Continuidade e mudança na gestão pública do estado do Pará. São Paulo, Paco edit.

POTTS, Jason (2009), "The innovation deficit in public services: The curious problem of too much efficiency and not enough waste and failure", en Innovation: Management, Policy \& Practice Journal, vol. 11:34-43. En línea: <https://www.researchgate.net/publication/41104736_The_innovation_deficit_in_public_services_The_ curious_problem_of_too_much_efficiency_and_not_enough_waste_and_failureDOI: 10.5172/impp.453.11.1.34> (consulta: 4 de marzo 2016). DOI: 10.5172/impp.453.11.1.34.

PRATS I CATALÁ, Joan (2000), "Reforma del Estado y Desarrollo Humano: una correlación problemática”, Quórum, núm. 1.

PRATS I CATALÁ, Joan (1993), Derecho y Management en las Administraciones Públicas. Notas sobre la crisis y renovación de los respectivos paradigmas. Barcelona, Instituto de Dirección y Gestión Pública, Papers de ESADE.

PolAVIEJA, Javier (2013), “Economic Crisis, Political Legitimacy, and Social Cohesion”, en GALLIE, DUNCAN (ed.), Economic Crisis, Quality of Work and Social Integration: The European Experience, Oxford, Oxford University Press.

POLLITT, Christopher (2008), La Innovación en el Sector Público, discurso de Apertura de la Conferencia Anual del Grupo Europeo de Administración Pública. Holanda, Erasmus Universiteit Rotterdam.

RAmió, Carles y SALVAdor, Miquel (2005), Instituciones y Nueva Gestión Pública en América Latina. Barcelona, Fundación CIDOB, Ediciones Bellaterra. 
RAMíREZ-AluJAS, Álvaro (2012), “Innovación en las Organizaciones y Servicios Públicos: ¿El Eslabón Perdido? Bases Para la Transición Hacia un Modelo de Innovación Abierta y Colaborativa”, en Revista Chilena de Administración Pública, núm. 19, pp. 5-50. En línea: <http://www.revistaeggp.uchile.cl/index.php/REGP/article/ viewFile/21177/22439> (consulta: 2 diciembre, 2015).

- (2010), Buen Gobierno. Innovación en la Gestión Pública y Open Government (Gobierno Abierto): Una Vieja Nueva Idea.

- (2011), "Gobierno abierto y modernización de la gestión pública: tendencias actuales y el (inevitable) camino que viene. Reflexiones seminales” en Revista Enfoques, IX(15):99-125. DOI: http://ssrn.com/abstract=1979133.

- (2010), “Innovación en la Gestión Pública y Open Government (Gobierno Abierto): Una vieja nueva idea”, Revista Buen Gobierno, núm. 9, México D. F.

RHODES, Roderick Arthur (1996), Governing without Governance: Order and Change in British Politics. Inaugural lecture, University of Newcastle upon Tyne, 18 April 1996.

RHODES, Roderick Arthur y David MARSH (1992), "Policy Network in British Politics", en David MARSH and Roderick A. RHODES (eds.), Policy Networks in British Government, Oxford: Clarendon Press, pp. 1-26.

StUfFLeBEAm Daniel (et. al.) (2002), Evaluation Models Viewpoints on Educational and Human Services Evaluation. Boston, Kluwer Academic, pp. 279-318.

SUBIRATS, Joan (2012), “¿Qué democracia y qué Administración para la nueva época? Internet y la gestión pública”, Ekonomiaz, 80(2): 70-91.

SULBRANDT, José (2002), Introducción a la gerencia social. Notas de Clase. Washington, D. C.: Instituto Interamericano para el Desarrollo Social (INDES). En línea: <http://indes.iadb.org/pub.asp> (consulta: 22 de junio de 2015).

TENórIO, Fernando G. (2008), “(Re)visitando o conceito de Gestão Social”, en SILVA JR., Jeová TORRES; MÂISH, Rogério Teixeira; CANÇAdo, Airton CARdoso; Schommer, Paula Chies. Gestão Social: Práticas em debate, teorias em construção. Fortaleza: Imprensa Universitária.

TORCAL, Mariano (2016), “Desafección política en España en una perspectiva comparada”, LLERA, Francisco, Desafección política y regeneración democrática en la España actual. Madrid, Centro de Estudios Políticos y Constitucionales.

TRUJILLO, Esther (et. al.) (2011), Manual de Gestión Pública Responsable. Madrid: Fundación Internacional y para Iberoamérica de Administración y Políticas (FIIAPP). En línea: <http://www.conr.es/descargas/FIIAPP_manual_ GPR.pdf> (consulta: 17 julio de 2016).

VAILLANCOURT, Yves (2009), "Social Economy in the co-Construction of public policy", en Annals of Public and Cooperative Economics, 80(2): 275-313, University of Quebec in Montreal, Canadá. DOI: 10.1111/j.14678292.2009.00387.x.

VALLÈS, Josep Maria (2016), “¿Regeneración democrática sin contexto? Las condiciones difíciles para un cambio”, en Llera, FRANCISCO, Desafección política y regeneración democrática en la España actual, Madrid, Centro de Estudios Políticos y Constitucionales.

WILLKE, Helmut (2001), Systemtheorie III: Steuerungstheorie. Konstanz/München UVK/UTB.

VILloria MENDIETA (2012), “El Gobierno Abierto como subsistema de políticas: una evaluación desde el institucionalismo discursivo” en HofmanN, Andrés, RAmírez AlujAs, Álvaro y Bojórquez PerezNieTo, José Antonio (2012), La Promesa del Gobierno Abierto. En línea: <http://inicio.ifai.org.mx/Publicaciones/La\%20 promesa\%20del\%20Gobierno\%20Abierto.pdf> (consulta: 13 febrero 2014).

Windrum, Paul y KoCH, Per (2008), Innovation in Public Sector Services. Entrepreneurship, Creativity and Management. Edward Elgar, Cheltenham.

Xu, Runya y SuN, Qigui; SI, Wei (2015), "The Third Wave of Public Administration: The New Public Governance", Canadian Social Science, 11(7):11-21. En línea: <http://journals.vaggi.org/browse/index/38?sortOrderld=\&records Page $=8>$ (consulta: 12 enero 2016). DOI: 10.3968/7354.

YSA, Tamyko (coord.); DE LA PEÑA, Maria; CRUSELLAS, Estel (2003), “Criterios para detectar buenas prácticas locales”, Document Pi i Sunyer, núm. 25, Barcelona. En línea: <http://www.bbp.cat/documentos/ CriteriosBPTamyko.pdf> (consulta: 10 marzo de 2014).

ZAPICO, Eduardo (2012), “Presentación”, Ekonomiaz, 80(2):7-19. 